\title{
Actuaciones del Defensor Universitario y su coordinación con las actuaciones de otros órganos de la Universidad
}

\author{
Actions of the University Ombuds Person and the coordination with the actions of other \\ University bodies
}

\author{
Juan Alberto Diez Ballesteros \\ Ex-Defensor Universitario de la Universidad de Alcalá \\ juan.diez@uah.es
}

\begin{abstract}
Resumen
El objetivo de este trabajo es exponer una serie de pautas generales que puedan servir de orientación a los Defensores Universitarios para resolver las posibles situaciones de conflicto que se pueden originar en la coordinación entre sus actuaciones y las de otros órganos de la Universidad. Se pretende ofrecer algunos criterios que permitan afrontar aquellos supuestos en los que se recibe una queja en la Defensoría pero, debido a que el órgano competente de la Universidad todavía no ha concluido su actuación, el Defensor debe decidir si comienza su intervención o suspende sus actuaciones.
\end{abstract}

Palabras clave: Defensor Universitario; actuaciones; normativa universitaria; actuaciones administrativas

\begin{abstract}
The aim of this paper is to set forth a series of general guidelines that can be useful as a guidance to the higher education Ombudsmen to resolve possible conflicts that may arise from the coordination between their actions and those of other University bodies. The purpose is to offer some principles that can make it possible to face those situations where a complaint is submitted to the Ombudsmen office before the competent body of the University has concluded a final decision. The Ombudsmen office must decide whether it starts to analyze the claim or it stop its own actions.
\end{abstract}

Keywords: Ombudsmen; University complaint; University bodies; administrative procedures.

Sumario. Introducción. 1-El Defensor Universitario: características y principios de actuación en la Ley Orgánica 6/2001, de 21 de diciembre, de Universidades. 2-La regulación interna de las Universidades. 3-La compatibilidad de la intervención de Defensor Universitario con las actuaciones de otros órganos universitarios. 4-Conclusiones. 5-Referencias. 


\section{Introducción}

El presente trabajo, en el que se recoge mi intervención en una de las mesas redondas del XXII Encuentro Estatal de Defensores Universitarios celebrado en la Universidad de Valladolid por la CEDU en octubre de 2019, tiene por objeto realizar un breve análisis de la coordinación de las actuaciones del Defensor Universitario (DU) con las intervenciones de otros órganos de la Universidad.

Se aborda un problema que se plantea habitualmente en el desarrollo cotidiano de la actividad de las Defensorías: cómo coordinar la actuación de la Defensoría con las actuaciones que se estuvieran realizando por otros órganos de la Universidad en relación con alguna queja presentada ante el DU.

En este trabajo se analiza, por consiguiente, la cuestión referida a si respecto de quejas o asuntos que ya están siendo tratados por otros órganos de la Universidad, el DU debe esperar en todo caso a que concluya la actuación del órgano competente, pese a que ello pudiera suponer la consumación de una eventual vulneración de los derechos de algún miembro de la comunidad universitaria, o bien el DU puede actuar en el ámbito de sus competencias legalmente establecidas, aunque la queja presentada ya esté siendo objeto de tramitación por la unidad correspondiente o no se hubieran agotado todos los recursos posibles en el ámbito interno de la propia Universidad.

Se pretende ofrecer una orientación para resolver el problema que se suscita con lo que algunos Defensores denominan actuaciones intermedias del DU, es decir, aquellas actuaciones que se realizan mientras otro órgano, competente sobre el asunto a resolver, está ya tramitando la cuestión. Este problema, aunque se puede suscitar con las consultas o las actuaciones de oficio, dado el carácter general que suelen tener las mismas, surge fundamentalmente en relación con las reclamaciones presentadas a instancia de parte por una o varias personas que solicitan el inicio de un expediente por parte de la Defensoría.

Tal situación, al menos desde mi experiencia, constituye una eventualidad frecuente en el desempeño ordinario de las Defensorías universitarias, en las que resulta habitual que, tras recibir una queja de un miembro de la comunidad universitaria, desde el órgano de la Universidad a quién corresponde la resolución del asunto sobre el que se ha recibido la reclamación, se alegue frente al DU que éste debe esperar a que concluya su actuación. Esta espera a la finalización de las actuaciones del órgano universitario competente, si bien resulta adecuada en términos generales, en algunas ocasiones puede suponer que se generen daños al quejoso o quejosos que han acudido a la Defensoría, que se emita una resolución administrativa que vulnere los derechos del solicitante $\mathrm{o}$, incluso, comportar un perjuicio para la Universidad, que tuviera que anular posteriormente sus actos o cambiar el criterio adoptado inicialmente.

Para abordar esta cuestión, expondré someramente las características principales de la figura del DU y sus principios de actuación en la LOU, la regulación interna de la institución en algunas de las universidades españolas y la compatibilidad de sus actuaciones con la intervención de otros órganos universitarios desde una perspectiva normativa. Dado que la regulación específica del régimen jurídico del DU depende de cada Universidad, realizaré una aproximación general a tales normativas de desarrollo sin una pretensión de exhaustividad. 
Lógicamente, anticipo que la respuesta a la cuestión planteada dependerá de la regulación propia de cada Universidad. No obstante, en las siguientes páginas trataré de ofrecer unos criterios generales que puedan ser de utilidad a los DDUU en el ejercicio de sus funciones, y que espero que puedan servir de base para posteriores trabajos sobre el tema.

\section{El Defensor universitario: características y principios de actuación en la Ley Orgánica 6/2001, de 21 de diciembre, de Universidades}

La figura del DU se encuentra regulada en la DA $14^{\mathrm{a}}$ de la Ley Orgánica 6/2001, de 21 de diciembre, de Universidades (LOU) según la cual:

\footnotetext{
Para velar por el respeto a los derechos y las libertades de los profesores, estudiantes y personal de administración y servicios, ante las actuaciones de los diferentes órganos y servicios universitarios, las Universidades establecerán en su estructura organizativa la figura del Defensor Universitario. Sus actuaciones, siempre dirigidas hacia la mejora de la calidad universitaria en todos sus ámbitos, no estarán sometidas a mandato imperativo de ninguna instancia universitaria y vendrán regidas por los principios de independencia y autonomía. Corresponderá a los Estatutos establecer el procedimiento para su elección o designación, duración de su mandato y dedicación, así como su régimen de funcionamiento.
}

Conforme a esta norma, todas las Universidades españolas, públicas y privadas, tienen la obligación de establecer, en el marco de su estructura, la figura del DU. Se trata, por tanto, de un órgano interno comisionado de diferentes órganos de la Universidad, normalmente el Claustro, que tiene por cometido velar por el respeto y la defensa de los derechos e intereses legítimos de todos los miembros de la comunidad universitaria y actuar para la mejora de la calidad de la Universidad.

Como tal órgano interno, anticipo ya esta idea a la que volveré posteriormente, su actuación no debe identificarse con la de un mero evaluador externo que desarrollaría su actividad de evaluación de las actuaciones de la Universidad a posteriori, cuando los órganos de la Universidad ya han agotado su tramitación o ya han actuado. Al contrario, el DU como tal órgano interno debe actuar en el propio ámbito de la Universidad, si bien de acuerdo con las competencias que tiene legalmente atribuidas y según el régimen de actuación que tenga reconocido en su propio reglamento o normativa interna de la Universidad en la que desempeña sus funciones.

En el ejercicio de sus funciones el DU:

1. Goza de completa autonomía e independencia de criterio en su actuación.

2. No está sujeto a mandato imperativo alguno, siendo un órgano independiente. Es decir, no se le podrán dirigir o dar instrucciones por parte de ninguna autoridad académica. Cuestión distinta es que deba rendir cuentas a otros órganos de la Universidad que le hayan elegido, como, por ejemplo, sería el caso del Claustro.

3. Goza de prerrogativas de inviolabilidad e inmunidad en su actuación. No podrá ser expedientado ni sancionado por las opiniones, recomendaciones que formule o actos que realice en el ejercicio de las competencias propias de su función, siempre que, lógicamente, tales actuaciones respeten el marco legal vigente. 
4. Ninguna materia que afecte a los derechos y libertades de los miembros de la comunidad universitaria le resulta ajena. Como la propia LOU indica su actuación se desarrolla en todos los ámbitos universitarios. En este sentido, el DU gozará en el ejercicio de sus funciones de una supervisión de 360 grados respecto de las actuaciones de los órganos e integrantes de la comunidad universitaria.

5. Debe ajustarse a la legislación de desarrollo específica de cada Universidad. Ahora bien, como expondré posteriormente, aunque cada Universidad tenga una regulación diferente, hasta donde he podido comprobar, las normativas coinciden en el principio de antiformalismo en las actuaciones del DU. El DU no es un órgano ejecutivo de la Universidad. Por tanto, sus actos no son recurribles y la presentación y tramitación de quejas, reclamaciones y consultas, si bien están sometidas a unos requisitos de admisión, en términos generales no están sujetas a los formalismos rígidos propios del derecho administrativo, ni suspenden plazos.

6. Su actuación se ve presidida por el principio de confidencialidad.

Todo ello convierte al Defensor en una figura con características propias y en muchos sentidos singular en el ámbito de las Universidades, lo que lógicamente determina también su forma de actuación.

Por consiguiente, de acuerdo con la LOU, la función primordial del DU es la de velar por el respeto a los derechos y las libertades de los miembros de la comunidad universitaria ante las actuaciones de los diferentes órganos y servicios de la Universidad. A esta función primordial debe añadirse la más genérica y abstracta de actuar por la mejora de la calidad universitaria en todos los ámbitos.

Es decir, el DU, en sus diversas denominaciones y acepciones en nuestras diferentes Universidades, debe garantizar la defensa de los derechos de todos los miembros de la comunidad universitaria frente a los actos de los órganos de la Universidad (o de alguno de sus integrantes) que constituyan o puedan constituir una vulneración de sus derechos. Además, debe actuar para la mejora de la calidad en todos los sectores de la Universidad.

Según el Diccionario de la RAE, el verbo velar tiene 10 acepciones diferentes ${ }^{1}$. De estas acepciones creo que pueden ser de interés en relación con este trabajo las siguientes: «hacer de centinela o guardia por la noche», «pasar la noche al cuidado de un difunto», «observar atentamente algo» y «cuidar solícitamente de algo». De estas posibles acepciones, considero que son aplicables al ejercicio de la actividad del DU aquellas que hacen referencia a su actuación como centinela o guardián, observando atentamente el funcionamiento de los diversos órganos de la Universidad, y al cuidado solicito de un asunto o queja que le haya sido encomendado.

Más allá de la acepción del verbo velar recogida por la RAE, debemos considerar que la LOU está haciendo referencia a una función de garantía, en el sentido de que el DU debe observar y controlar que se respeta el cumplimiento de la legislación vigente y los derechos y libertades de los miembros de comunidad universitaria. Por consiguiente, el cometido esencial del DU es supervisar la actuación de los diferentes órganos de la Universidad y garantizar que dicha actuación respeta los derechos de los universitarios y se ajusta a la legalidad.

\footnotetext{
${ }^{1}$ https://dle.rae.es/velar?m=form, consulta realizada el 20 de mayo de 2020.
} 
Descarto, por tanto, que la función del DU pueda ser, incluso metafóricamente, la de pasar la noche al cuidado de un difunto, aunque quizá, dicho en términos humorísticos, si se limitan en exceso sus posibilidades de intervención, ese podría ser el resultado en relación con algunos asuntos, en los que, si el DU no pudiera intervenir de ningún modo hasta la conclusión de las actuaciones de los diferentes órganos competentes de las Universidad, actuaría realmente como un médico forense.

Ahorabien, en el cumplimiento de esta función o competencia esencial de supervisión y garantía, más allá de otras atribuidas de forma más concreta en los estatutos y normativa interna de cada universidad, el DU debe respetar la asignación competencial que corresponde conforme al derecho administrativo a cada órgano, unidad o servicio de la Universidad. El derecho administrativo tiene por criterio principal la atribución de competencias específicas a cada órgano de la administración, de manera que el DU deberá respetar en todo caso esa atribución competencial. Además, en esa función de velar por los derechos de los miembros de la comunidad universitaria no puede sustituir a otros órganos o servicios que tengan legalmente atribuida la competencia respecto del asunto, solicitud o cuestión de la que se trate.

No obstante, el respeto de la asignación competencial establecida no impide conocer al DU de los temas, quejas o reclamaciones que reciba a instancia de parte siempre y cuando entren dentro de su ámbito propio de competencia. Ello implica, en primer lugar, que la actuación de la Universidad, o de alguno de sus integrantes, afecte a los derechos y libertades de miembros de la comunidad universitaria de acuerdo con la legislación vigente. De este modo, quedaría excluida la intervención del DU en los supuestos en los que meramente se planteara un mero disgusto o disconformidad del quejoso con la actuación de la Universidad si dicha actuación cuenta el respaldo legal oportuno. En tales casos debe rechazarse la petición por falta de fundamento, con independencia de que el DU pueda posteriormente analizar si cabe la posibilidad de recomendar un cambio en la normativa vigente. En segundo lugar, es preciso que la actuación del DU se ajuste a la normativa interna propia de la Universidad de la que forma parte, que es la que delimita de forma concreta y específica cuál es su régimen propio de actuación.

\section{La regulación interna de las Universidades}

Como la propia Disposición adicional $14^{\mathrm{a}}$ de la LOU establece, corresponde a la normativa de desarrollo de cada Universidad determinar el procedimiento de elección y duración del mandato del DU, así como, en lo que aquí interesa, su régimen de actuación y funcionamiento.

Este precepto es la plasmación del principio de autonomía universitaria recogido en el artículo 27.10 de la Constitución Española ${ }^{2}$ implica que será la propia normativa de cada Universidad (los estatutos y reglamentos internos) la que desarrollará y regulará el régimen de actuación propio del DU. Así lo han hecho las universidades españolas, incluyendo la institución del DU en sus respectivos estatutos y aprobando los propios reglamentos de organización y funcionamiento de sus Defensorías.

Esta normativa interna, en mi opinión, tiene como límite el llamado principio o teoría de las garantías institucionales, que considero que resultaría de aplicación en

\footnotetext{
${ }^{2}$ Artículo 27.10 CE: Se reconoce la autonomía de las Universidades, en los términos que la ley establezca.
} 
el caso de la institución del $\mathrm{DU}^{3}$. De acuerdo con este principio, propio del derecho constitucional, la figura del DU, reconocida expresamente como una institución estructural de las Universidades, debe ser garantizada de manera que los desarrollos normativos que se hayan efectuado o efectúen en el futuro preserven y respeten en su contenido esencial la figura, manteniendo la institución en términos plenamente reconocibles.

Por tanto, aunque las Universidades gozan de un amplio margen para regular el régimen de elección, funcionamiento y cese del DU, siempre deberán respetar el contenido esencial de la institución, preservando el cometido que le tiene asignado la LOU. No resultaría admisible, entonces, una regulación interna de desarrollo tan limitativa que dejase vacía de contenido la figura, impidiendo el ejercicio de las funciones que la LOU ha atribuido expresamente al DU.

El DU constituye una institución estructural de las Universidades españolas cuya existencia debe ser garantizada y los desarrollos normativos que se realicen regulando la misma deben respetar su contenido esencial, sin desnaturalizarla, preservando la institución en términos reconocibles.

Como es sabido, las Universidades españolas han procedido paulatinamente a la aprobación de una regulación específica de la figura del DU, tanto en sus estatutos como en las diversas normativas o reglamentos internos. Dichas normativas son las que, a la postre, de forma concreta configuran el régimen de intervención del DU, ya que, por lo general, la regulación estatutaria suele recoger los términos de la LOU y una regulación muy básica de la figura y sus funciones. Por consiguiente, para resolver la cuestión de la coordinación de la intervención del DU con las actuaciones de otros órganos universitarios deberemos atender a regulación propia de cada Universidad.

\section{La compatibilidad de la intervención del Defensor Universitario con las actuaciones de otros órganos universitarios}

Abordando ya la cuestión de la coordinación y compatibilidad de las actuaciones del DU en el ejercicio de sus funciones con las de otros órganos universitarios, o incluso extrauniversitarios, si bien las normativas internas de las universidades varían, podríamos agrupar las soluciones que se ofrecen del siguiente modo:

- Normativas que determinan la inadmisión o suspensión de la reclamación o queja por litispendencia judicial o administrativa.

- Normativas que determinan la inadmisión o suspensión de la reclamación por existir ya una tramitación del asunto por otros órganos universitarios o por no haberse agotado los recursos internos.

- Normativas que no establecen expresamente la inhibición del DU mientras actúa el órgano universitario competente o no se han agotado los recursos.

\footnotetext{
3 Sobre la doctrina de las garantías institucionales véanse, entre otras, SSTC 5/1981 de 13 de febrero, 32/1981 de 28 de junio y 26/1987 de 27 febrero. Desde una perspectiva doctrinal, véase LEÓN ALONSO, M., «La recepción en España de la teoría de las garantías institucionales», en AAVV, La protección constitucional de la salud, editorial la Ley, Madrid 2010.
} 
Procederé a exponer someramente cada una de estas situaciones.

\subsection{Normativas que determinan la inadmisión o suspensión de la reclamación por litispendencia judicial o administrativa}

Hasta donde conozco, sin pretensión de exhaustividad, las regulaciones internas de las universidades normalmente establecen expresamente el deber del DU de suspender sus actuaciones, si ya se hubiera iniciado una tramitación, o no entrar a conocer las quejas o solicitudes a instancia de parte cuando ya existe un procedimiento sobre el asunto en sede judicial, o, en su caso, interposición de demanda o denuncia o pendiente de resolución judicial, o bien, en algunos casos, un expediente administrativo (art. 18 RDUUAH $^{4}$, art. 8 RDUUAM $^{5}$, art 10 RDUURYJC $^{6}$, art. 20 RDUUPO $^{7}$, art. 10.4 RDUUC3M $^{8}$, art. 13.2 RDUUVA ${ }^{9}$, art.

\footnotetext{
4 Art. 18 RDUUAH: «Rechazo de peticiones y suspensión de la tramitación. El Defensor Universitario rechazará las consultas, quejas o reclamaciones anónimas, así como las formuladas con insuficiente fundamentación. En el caso de aquellos asuntos sobre los que esté pendiente resolución judicial o expediente administrativo, se suspenderá la tramitación, sin perjuicio de que se investiguen los problemas generales planteados en ellas y se emitan las recomendaciones genéricas pertinentes».
}

5 Artículo 8 RDUUAM: «Tramitación de las solicitudes. 1. El Defensor no admitirá las solicitudes anónimas, las formuladas con insuficiente fundamentación o inexistencia de pretensión y todas aquellas cuya tramitación cause un perjuicio al derecho legítimo de una tercera persona. En todo caso, el Defensor del Universitario comunicará por escrito a la persona o personas interesadas los motivos de la no admisión. 2. El Defensor del Universitario rechazará aquellas solicitudes sobre las que no se hayan agotado todas las instancias previstas por la legislación universitaria aplicable, indicando los procedimientos adecuados. Sin embargo, podrá aceptarlas en aquellos casos en los que, sin haberse agotado la instancia, considere que puede aportar información relevante para la resolución del procedimiento o en que se requiera la urgencia de la resolución. 3. El Defensor no entrará en el examen individual de aquéllas solicitudes sobre las que esté pendiente resolución judicial y suspenderá cualquier actuación si, una vez iniciada, se interpusiese demanda o recurso ante los Tribunales por persona interesada. Ello no impedirá, sin embargo, que el Defensor del Universitario actúe de oficio en el examen de los problemas generales derivados de dichas solicitudes».

6 Artículo 10 RDUURJC: «El Defensor Universitario rechazará las observaciones, reclamaciones y quejas anónimas, las formuladas con insuficiente fundamentación o inexistencia de pretensión, así como todas aquellas cuya tramitación cause un perjuicio al derecho legítimo de terceras personas. En todo caso, comunicará por escrito a las personas interesadas los motivos del rechazo. El Defensor Universitario no entrará en el examen individual de aquellas quejas sobre las que esté pendiente resolución judicial o expediente administrativo, y suspenderá cualquier actuación si, una vez iniciada, se interpusiese demanda o recurso ante los tribunales por las personas interesadas. No obstante, ello no impedirá que el Defensor examine los problemas generales planteados en las quejas o reclamaciones presentadas».

7 Artículo 20 RDUUPO. «Admisión y plazo de resolución. 1. Cuando se presente una queja o reclamación, la oficina de la Defensoría Universitaria la registrará y acusará recibo de la misma en el plazo máximo de una semana, procediendo a tramitarla o a inadmitirla de forma motivada. Esta última medida cabrá cuando la petición exceda de las competencias de la Defensoría Universitaria, cuando en el asunto esté pendiente una resolución judicial o administrativa o cuando no se hayan agotado todas las instancias y recursos previstos en los Estatutos de la Universidad».

8 Artículo 10.4 RDUUC3M: «El Defensor Universitario no entrará en el examen de aquellas solicitudes o quejas sobre las que esté pendiente resolución judicial y suspenderá su actuación si, una vez iniciada, se interpusiere por persona interesada cualquier acción o recurso ante los Juzgados y Tribunales».

9 Artículo 13.2 RDUUVA: «El Defensor no entrará en el examen individual de aquellas quejas sobre las que esté pendiente resolución judicial o expediente administrativo sancionador y lo suspenderá si, iniciada su actuación, se interpusiera por persona interesada demanda o recurso ante los Tribunales ordinarios. Ello no impedirá, sin embargo, la investigación de los problemas generales planteados en las quejas presentadas. En cualquier caso, velará porque la Universidad resuelva expresamente, en tiempo y forma, las peticiones y recursos que le hayan sido formulados». 
7 RSDGUV ${ }^{10}$, art. 9.1 d) RDSGUB ${ }^{11}$ y art. 8.3 RDUUMA ${ }^{12}$ ).

En algún supuesto, además, el deber de abstenerse de actuar cuando ya existe una intervención de la jurisdicción se establece de forma taxativa, como sucede en el art. 4.4 RDUUAL, según el cual «en ningún caso intervendrá el/la Defensor Universitario/a en asuntos en relación con los que se haya interpuesto recurso jurisdiccional, ni en procedimientos electorales».

La inadmisión de reclamaciones individuales, o la suspensión de actuaciones si ya se habían iniciado, resulta razonable y justificada en los supuestos en lo que ya existe intervención de los tribunales de justicia. Cuando ya se ha iniciado una tramitación del asunto o controversia en sede judicial, los tribunales garantizarán el cumplimiento de la legislación vigente y el control de una posible vulneración de derechos del miembro de la comunidad universitaria que pudiera estar afectado. Esta situación supone la salida de la gestión y resolución del conflicto fuera del ámbito intra universitario y su entrada en el ámbito jurisdiccional, en virtud del derecho constitucionalmente reconocido de tutela judicial efectiva (art. 24.1 CE) ${ }^{13}$. Las decisiones de los jueces y tribunales serán soberanas y deberán ser aplicadas, en su caso, por la Universidad, teniendo el valor de cosa juzgada.

En algunas ocasiones las universidades incluyen este deber de abstención también cuando existe ya un expediente administrativo en relación con el asunto que se ha planteado a instancia de parte ante el DU. En mi opinión, la referencia a la existencia de un expediente administrativo debe entenderse realizada a la instrucción de expedientes disciplinarios en el ámbito de la inspección de servicios u órganos análogos, no a cualquier actuación administrativa de la Universidad. Así se puntualiza expresamente en el art. 13.2 RDUUVA o el art 5. RDUUM ${ }^{14}$, art. 12 RTGUVigo y Art. 14.2 RDUUS ${ }^{15}$.

10 Artículo 7.2 RSDGUV: «La Sindicatura no entrará a examinar individualmente las quejas pendientes de resolución judicial o expediente administrativo y suspenderá cualquier actuación iniciada cuando se plantee demanda o recurso ante los tribunales ordinarios. Eso no impedirá la investigación de los problemas generales que se puedan identificar en las quejas presentadas».

11 Article 91 RSDGUB: «No seran admeses les queixes i les reclamacions següents: a) Les de caràcter anònim. b) Les formulades amb evident mala fe o amb perjudici dels drets o interessos legítims de terceres persones. c) Les que no tinguin versemblança, pretensió concreta o suficient fonamentació. d) Les pendents de resolució judicial; amb suspensió d'actuacions si durant aquestes, la persona interessada interposa demanda o recurs davant els tribunals».

12 Artículo 8.3 RDCUUMA: «El/La Defensor/a Universitario/a no podrá tramitar quejas o reclamaciones sobre cuestiones pendientes de resolución judicial y las suspenderá si, iniciada su actuación, se interpusiese por persona interesada demanda o recurso ante los Tribunales. Ello no impedirá, sin embargo, la investigación sobre los problemas generales suscitados por dichas quejas».

13 Artículo 24.1 CE: «Todas las personas tienen derecho a obtener la tutela efectiva de los jueces y tribunales en el ejercicio de sus derechos e intereses legítimos, sin que, en ningún caso, pueda producirse indefensión».

14 Art. 5 RDUUM: «No se podrán admitir reclamaciones sobre las que esté pendiente un proceso jurisdiccional ni un expediente disciplinario administrativo».

15 Artículo 14 RDUUS: «Litispendencia administrativa o judicial 1. El Defensor Universitario no entrará en el examen individual de aquellas quejas sobre las que esté pendiente una resolución judicial o administrativa. 2. En caso de haber iniciado un procedimiento, lo suspenderá si se interpusiera por cualquiera de los interesados recurso, reclamación o demanda en vía administrativa o ante los tribunales ordinarios o el Tribunal Constitucional, sobre el mismo asunto, o si se les incoara expediente sancionador en la Universidad de Sevilla. Ello no impedirá, sin embargo, la investigación sobre los problemas generales planteados en las quejas presentadas». 
Sin embargo, este deber de suspender o inadmitir la tramitación en estos supuestos puede no impedir, como se dispone expresamente en algunas normativas (art. 18 RDUUAH, art. 8 RDUUAM, art. 28 RDUUCM $^{16}$, art. 20 RDUUPO, art. 7 RSGUV, art. 10 RDUURJC, art. 6.4 RDUUCLM $^{17}$, Art. 14.2 RDUUS), que el DU pueda investigar los problemas generales planteados en relación con tales quejas o la emisión de recomendaciones de carácter general respecto al problema planteado.

En estos casos, en los que la normativa contiene expresamente la salvedad de poder proceder a un estudio del problema desde una perspectiva general, el DU, en el ejercicio de sus competencias o funciones de supervisión y garantía, podría actuar y emitir recomendaciones de carácter general a los órganos competentes de la Universidad. No podría pronunciarse en cambio, respecto de la queja individual o caso concreto en el que se hubiera solicitado su intervención.

Esta opción me parece razonable, dado que atiende a la singularidad de la figura del DU y su función de participar en la mejora de la calidad universitaria. No obstante, considero que en estos supuestos el DU deberá ser muy cauteloso y actuar con prudencia, de modo que su intervención, aunque adopte una perspectiva general respecto del problema planteado, sea muy meditada.

\subsection{Inadmisión o suspensión de la reclamación por existir tramitación de otros órganos universitarios o no haberse agotado los recursos internos}

Algunas normativas incluyen expresamente el deber de rechazar las solicitudes presentadas ante la Defensoría cuando no se hayan agotado todas las instancias previstas por la legislación universitaria aplicable o los recursos internos (vgr. art. 8 RDUUAM, art 20 RDUUPO, art. 9.1 f) RSGUB ${ }^{18}$ ).

Tal regulación implica que el DU debe abstenerse de conocer sobre tales peticiones hasta que exista una resolución del órgano administrativo competente, o incluso hasta el agotamiento de la vía administrativa. Con ello queda vedada, en principio, cualquier actuación sobre la cuestión planteada en la solicitud por parte del DU hasta la resolución del asunto por el órgano universitario competente o mientras no se hayan agotados los recursos administrativos previstos.

Ahora bien, algunas universidades que han recogido una regla así en su reglamento, como por ejemplo la Universidad de Granada, no permiten en estos casos pronunciarse sobre el fondo concreto de la queja concreta presentada, pero sí autorizan investigar los problemas planteados en conexión con la misma o bien tramitar el expediente

\footnotetext{
16 Art. 16 RDUUCM: «El Defensor Universitario no entrará en el examen individual de aquellas quejas sobre las que esté pendiente resolución judicial o expediente administrativo y suspenderá cualquier actuación si, en el transcurso de su tramitación, se iniciara un procedimiento administrativo o se interpusiera demanda o recurso ante los tribunales ordinarios. Ello no impedirá, sin embargo, la investigación de los problemas generales planteados en las quejas presentadas».

17 Art. 6.4 RDUUCLM: «El Defensor Universitario no entrará en el examen de aquellas solicitudes y quejas sobre las que esté pendiente resolución judicial, y suspenderá cualquier actuación si, una vez iniciada, se interpusiese demanda o recurso ante los tribunales por persona interesada. Ello no impedirá, sin embargo, el examen de los problemas generales planteados en las solicitudes y quejas presentadas».

18 Art. 9.1 f) RSGUB: «No seran admeses les queixes i les reclamacions següents: $\mathrm{f}$ ) Les que no hagin esgotat totes les instàncies de resolució previstes per la normativa administrativa aplicable».
} 
como una solicitud de mediación ante el órgano universitario correspondiente que esté tramitando la petición concreta del quejoso (art. 16 RDUUGR ${ }^{19}$ ).

En un sentido similar se pronuncia el art. 16.7 y 8 del RDUUAL al disponer:

16.7. Cuando se reciba una queja con relación a un asunto que se esté tramitando y no se hayan agotado todas las instancias y recursos previstos en la normativa vigente, el/la Defensor/a Universitario/a podrá investigar los problemas planteados en conexión con la queja y solicitar la información que necesite, pero no podrá pronunciarse sobre el fondo de la misma ni utilizar los pronunciamientos formales a que se refiere el artículo 20.1 de este reglamento.

16.8. También podrá el/la Defensor/a Universitario/a, cuando esté en trámite un expediente administrativo o un recurso interno ante los órganos universitarios, tramitar el asunto como una solicitud de mediación, conforme a lo previsto en el Capítulo Tercero de este Título. En tal caso, se requerirá el consentimiento expreso de todas las partes implicadas. El órgano administrativo ante el que se esté tramitando el expediente o recurso suspenderá provisionalmente el procedimiento, una vez aceptada la mediación por el/la Defensor/a, mientras ésta se esté sustanciando, siempre y cuando la suspensión no provoque la vulneración de algún plazo legal o una decisión administrativa no ajustada a derecho.

Es decir, en las circunstancias expuestas cabría la investigación de los problemas conexos planteados en relación con la queja y solicitar información al órgano correspondiente, fijándose como límite de la actuación del DU que no realice pronunciamiento formal sobre el fondo del asunto.

También precisa la limitación de la intervención del DU en estas circunstancias el art 8 del RDUUAM, conforme al cual:

2. El Defensor del Universitario rechazará aquellas solicitudes sobre las que no se hayan agotado todas las instancias previstas por la legislación universitaria aplicable, indicando los procedimientos adecuados. Sin embargo, podrá aceptarlas en aquellos casos en los que, sin haberse agotado la instancia, considere que puede aportar información relevante para la resolución del procedimiento o en que se requiera la urgencia de la resolución.

Por tanto, el DU puede intervenir si su actuación aporta información relevante para resolver el procedimiento administrativo en curso o bien en supuestos de urgencia de la resolución.

La regla de inhibición temporal según la cual el DU no debe intervenir si existe ya una tramitación por otro órgano universitario sobre la cuestión o bien no se han agotado todos los recursos internos, resulta, a mi juicio, razonable en términos generales y como principio. De acuerdo con un criterio de prudencia en sus actuaciones, resulta lógico que, en general, el DU deba esperar a que el órgano competente de la Universidad, al que el DU en ningún caso puede sustituir, resuelva la petición o solicitud planteada. Esta regla encontraría su fundamento en el objetivo de evitar solapamientos de las actuaciones entre diferentes unidades o servicios de la misma Universidad. Además, así se evita una actua-

19 «7. Cuando se reciba una queja con relación a un asunto que se esté tramitando y no se hayan agotado todas las instancias y recursos previstos en los Estatutos, el Defensor Universitario podrá investigar los problemas planteados en conexión con la queja y solicitar la 8 información que necesite, pero no podrá pronunciarse sobre el fondo de la misma ni utilizar los pronunciamientos formales a que se refiere el artículo 21.1 de éste reglamento. 8. También podrá el Defensor Universitario, cuando esté en trámite un expediente administrativo o un recurso interno ante los órganos universitarios, tramitar el asunto como una solicitud de mediación, conforme a lo previsto en el Capítulo Tercero de este Título. En tal caso, se requerirá el consentimiento expreso de todas las partes implicadas. El órgano administrativo ante el que se esté tramitando el expediente o recurso suspenderá provisionalmente el procedimiento, una vez aceptada la mediación por el Defensor, mientras ésta se esté sustanciando». 
ción prematura del DU que pudiera estar injustificada por un órgano que, además, no tiene carácter ejecutivo.

Cuando la normativa expresamente establezca la no intervención del DU en estas circunstancias sin excepción alguna, estimo que el DU no podrá actuar, en principio, ni siquiera para realizar un estudio o análisis general del problema planteado. Tal opción normativa se ajusta al amplio margen de configuración de la figura que tienen las Universidades, si bien, como ya he puesto de manifiesto, siempre debe respetarse el contenido esencial de la misma.

Ahora bien, en la práctica esta opción regulatoria puede plantear problemas reales como, por ejemplo, que resulte previsible una producción de daños irreparables o de difícil restitución, o bien que se tenga conocimiento de una tramitación torcida o irregular por el órgano correspondiente o se constate una dilación indebida o injustificada en la tramitación, o, incluso, que se pueda plantear por el quejoso una mediación.

Partiendo de la base de que cuando la normativa interna de la Universidad haya vetado expresamente la intervención del DU hasta el agotamiento de las instancias competentes debe respetarse este criterio, creo que excepcionalmente en las hipótesis mencionadas, se puede sostener que cabría una intervención del DU para pedir información a fin de poder evaluar su propia competencia y la situación del expediente administrativo.

Además, dadas las singulares características de la figura del DU, el informalismo que la rige, su deber de garante de derechos y las funciones supervisoras y de mejora de la calidad de la Universidad que tiene atribuidas, excepcionalmente también sería admisible, en mi opinión, una intervención temprana del DU para plantear una posible mediación (como por ejemplo se admite expresamente en el art. 9.3 del RSGUB ${ }^{20}$ ).

También estimo que sería admisible una intervención del DU aunque ya se estuviera realizando una tramitación por el órgano universitario correspondiente cuando concurrieran razones de urgencia o gravedad en relación con el asunto planteado.

Por último, cabría también su intervención, como se ha establecido en algún reglamento interno, cuando se constate una dilación indebida de la resolución. En tal sentido se pronuncia el art. 8.4 del RDUUMA según el cual el DU «en todo caso velará porque la Administración universitaria resuelva expresamente, en tiempo y forma, las peticiones y recursos que se le presenten». Si la causa de la inacción del DU se justifica en la tramitación por parte de la unidad o servicio competente de la Universidad, sería posible intervenir si se tiene constancia de que tal actuación no se está material y efectivamente realizando o se está demorando de forma injustificada. En caso contrario se podría producir una situación de indefensión para el quejoso o solicitante de amparo.

En este sentido, debo recordar que el DU no es un mero evaluador externo de una agencia de evaluación, con una función de supervisión ex post. Se trata de un órgano interno de la Universidad cuyo cometido es velar por el cumplimiento de la normativa, no evaluar $a$ posteriori la tramitación de los expedientes.

20 «Tanmateix, en determinats casos, els afectats podran consultar directament amb el síndic o síndica sobre la conveniència de la seva mediació sense esperar l'esgotament de la via administrativa universitària». 
Sin embargo, como ya he indicado, en los supuestos en los que la normativa interna así lo establezca, la regla debe ser la inhibición temporal del DU hasta que los órganos competentes de la Universidad hayan resuelto o se hayan pronunciado sobre la cuestión.

\subsection{Normativas que no establecen expresamente la inhibición del DU mientras actúa el órgano universitario competente o no se han agotado los recursos}

Otros reglamentos internos no contemplan expresamente la existencia de actuación del órgano competente de la Universidad entre las causas de no tramitación de las solicitudes presentadas ante la Defensoría. Sencillamente se guarda silencio al respecto (RDUUAH, RDUUCM, RDUUC3M, RDUUCLM, entre otros).

A mi juicio, como principio general, aunque no se establezca explícitamente, se debe respetar en lo posible el criterio de que la intervención del DU debe producirse tras el agotamiento de las vías académicas competentes sobre el asunto del que se trate. Este criterio, en primer lugar, se ajusta al respeto de la atribución competencial en el ámbito administrativo, así como a la no sustitución de otros órganos universitarios con capacidad ejecutiva.

En segundo lugar, con este criterio se evitan actuaciones apresuradas y prematuras, que, por otro lado, pueden perjudicar la visibilidad de la institución del DU en el ámbito de la Universidad. Además, de este modo se evita una intervención inadecuada en asuntos poco relevantes o de fácil solución que normalmente el órgano competente resolverá en poco tiempo.

Ahora bien, en los casos en los que la normativa interna no contiene una expresa limitación de las actuaciones del DU, la posibilidad de intervención del DU es mayor. La intervención del DU en estos supuestos, que debería realizarse con prudencia y cautela, puede fundamentarse en:

1. La función de garante interno al que ninguna materia de la universidad le es ajena, El DU no sustituye al órgano competente, pero eso no le impide conocer de los problemas o cuestiones de su competencia.

2. La atribución competencial del DU, con la posibilidad de estudio de asuntos y recomendaciones de carácter general, permite que el DU superponga su actuación a la de la unidad universitaria correspondiente, siempre que no pretenda sustituirla.

3. El carácter no ejecutivo y el antiformalismo de la institución, así como el deber de colaboración que tienen todos los órganos internos de la Universidad con las Defensorías.

4. En los principios reconocidos en el art. 3 de la Ley 40/2015, de régimen jurídico del sector público ${ }^{21}$. En especial, se podría basar la actuación en los principios

21 Art. 3 Ley 40/2015, de 1 de octubre, de régimen jurídico del sector público, $\mathrm{BOE} \mathrm{n}^{\circ}$ 236, de 2 de octubre de 2015: «1. Las Administraciones Públicas sirven con objetividad los intereses generales y actúan de acuerdo con los principios de eficacia, jerarquía, descentralización, desconcentración y coordinación, con sometimiento pleno a la Constitución, a la Ley y al Derecho. Deberán respetar en su actuación y relaciones los siguientes principios: a) Servicio efectivo a los ciudadanos. b) Simplicidad, claridad y proximidad a los ciudadanos. c) Participación, objetividad y transparencia de la actuación administrativa. d) Racionalización y agilidad de los 
de servicio efectivo a los ciudadanos, la objetividad y transparencia de la actuación administrativa y la racionalización y agilidad de los procedimientos administrativos y de las actividades materiales de gestión. Aunque según dispone el art. 2.2 de la referida ley, las Universidades públicas se regirán por su normativa específica, también se reconoce la aplicación supletoria de la Ley $40 / 2015^{22}$.

Por consiguiente, esta actuación excepcional o temprana del DU, a mi juicio, estaría justificada en los supuestos siguientes:

1. Solicitudes de mediación, arbitraje o conciliación en relación con el asunto que está siendo tramitado.

2. Existencia de dilaciones indebidas o anormales en la tramitación por el órgano competente.

3. Razones de urgencia o gravedad de los hechos, que justificasen suficientemente la intervención del DU.

4. Posibles daños irreparables o de difícil restitución que una posible intervención del DU pudiera evitar, incluyendo riesgos psico-físicos para los integrantes de la comunidad universitaria.

5. Tener información relevante por razón de su cargo para la adecuada tramitación administrativa de la cuestión que el órgano competente pudiera desconocer.

6. Asuntos de ámbito general que pudieran tener un amplio nivel de afectación entre los miembros de la comunidad universitaria.

7. Conocimiento o sospecha racional y fundada de incumplimientos flagrantes de la legislación o irregularidades en la tramitación del expediente.

No obstante, en estas circunstancias el DU deberá, a mi juicio, valorar convenientemente las circunstancias concurrentes para decidir si resulta procedente o no su intervención, con arreglo a un criterio de prudencia y de eficacia de su actuación.

procedimientos administrativos y de las actividades materiales de gestión. e) Buena fe, confianza legítima y lealtad institucional. f) Responsabilidad por la gestión pública. g) Planificación y dirección por objetivos y control de la gestión y evaluación de los resultados de las políticas públicas. h) Eficacia en el cumplimiento de los objetivos fijados. i) Economía, suficiencia y adecuación estricta de los medios a los fines institucionales. j) Eficiencia en la asignación y utilización de los recursos públicos. k) Cooperación, colaboración y coordinación entre las Administraciones Públicas. 2. Las Administraciones Públicas se relacionarán entre sí y con sus órganos, organismos públicos y entidades vinculados o dependientes a través de medios electrónicos, que aseguren la interoperabilidad y seguridad de los sistemas y soluciones adoptadas por cada una de ellas, garantizarán la protección de los datos de carácter personal, y facilitarán preferentemente la prestación conjunta de servicios a los interesados. 3. Bajo la dirección del Gobierno de la Nación, de los órganos de gobierno de las Comunidades Autónomas y de los correspondientes de las Entidades Locales, la actuación de la Administración Pública respectiva se desarrolla para alcanzar los objetivos que establecen las leyes y el resto del ordenamiento jurídico».

22 Artículo 2.2 c) Ley 40/2015: «El sector público institucional se integra por c) Las Universidades públicas que se regirán por su normativa específica y supletoriamente por las previsiones de la presente Ley». 


\section{Conclusiones}

De acuerdo con lo expuesto, pueden sostenerse las siguientes conclusiones:

1. La actuación del DU, como vigilante y garante de los derechos y libertades de los miembros de la comunidad universitaria, debe ajustarse a las competencias atribuidas en la LOU y en la normativa interna propia de cada Universidad. Será cada reglamento interno el que delimitará las posibilidades de actuación del DU cuando exista tramitación del asunto por otros órganos de la Universidad o no se hayan agotado los recursos o vías internas.

2. El DU no podrá abordar reclamaciones a instancia de parte cuando exista intervención judicial, litispendencia judicial o se haya iniciado un expediente disciplinario sancionador. En estos casos, cabría la posibilidad excepcional de hacer un análisis de carácter general sobre los problemas planteados, si el reglamento interno lo admite.

3. Si la normativa interna expresamente establece el deber de abstención o inhibición, el DU deberá rechazar la solicitud o suspender su actuación hasta la conclusión de la tramitación o agotamiento de los recursos internos en la Universidad. De forma excepcional cabría intervenir en los casos de ofrecimiento de mediación, razones de urgencia o gravedad, o una posible puesta en conocimiento hechos relevantes sobre el asunto al servicio competente.

4. Si la normativa no establece tal limitación, hay mayores márgenes de intervención, en los términos expuestos previamente, aunque respetando la regla general de prudencia en la actuación.

5. Se puede mantener la intervención del DU en supuestos tales como solicitudes de mediación en relación con el expediente administrativo en trámite, la existencia de dilaciones anormales en la tramitación por el órgano competente, la posible previsión de daños irreparables, tener información relevante para la adecuada tramitación del procedimiento administrativo o tener conocimiento de incumplimientos flagrantes de la legislación.

\section{Referencias}

Acale Sánchez, Ma ; Baraja Rodríguez, E.; Guillamón Fernández, J. R, «Derecho disciplinario y seguridad jurídica», Revista Rued@, noviembre 2016, pp. 99 y ss.

Gamero Casado, E., «La calidad de la docencia: sistemas de evaluación y de incentivos de la calidad docente. La figura del Defensor Universitario en la mejora de la calidad de la docencia», en La figura del defensor universitario: garantía de derechos, libertades y calidad en las universidades, Alcover de la Hera, C.M, (coordinador), Universidad Internacional de Andalucía, Abril 2008, pp. 63 y ss.

González Aguado, $M^{\mathrm{a}}$. $\mathrm{T}^{\mathrm{a}}$, «El Defensor: una pieza clave en el nuevo escenario universitario español», en La figura del defensor universitario: garantía de derechos, libertades y calidad en las universidades, Alcover de la Hera, C.M, (coordinador), Universidad Internacional de Andalucía, Abril 2008, pp. 15 y ss.

Palazón Espinosa, J., «Las Defensorías Universitarias como instrumento para la mejora de las Universidades», Revisa Rued@, n² 2, 2017, pp.63 y ss. 